lợi để nhóm nghiên cứu có thể thu thập số liệu và hoàn thành nghiên cứu.

\section{TÀI LIỆ THAM KHẢO}

1. Martinez FD, Wright $A L$, Taussig $L M$, et al. Asthma and wheezing in the first six years of life. The Group Health Medical Associates. N Engl ] Med. 1995; 332(3): 133-138. doi:10.1056/NEJM199501193320301

2. Spycher BD, Silverman $M$, Kuehni CE. Phenotypes of childhood asthma: are they real? Clin Exp Allergy. 2010;40(8):1130-1141. doi:10.1111/j.1365-2222.2010.03541.x

3. Hoàng Thị Thanh Mai. Nghiên cứu môt số kiểu hình khò khè thường gặp ở trẻ dưới 5 tuổi tại bênh viện Nhi Trung Ương. Luận văn Bác sỹ nội trú, Trường Đai hoc Y Hà Nôi. 2018

4. Nguyến Thị Hà. Nghiên cứu nguyyên nhân khò khè ớ trẻ dưới 5 tuối tại khoa miến dịch-dị ứngkhớp bệnh viện Nhi Trung Ương. Luân văn Bác sỹ nội trú, Trường Đại học Y Hà Nội. 2013

5. Brand PLP, Baraldi E, Bisgaard $H$ et al.
Definition, assessment and treatment of wheezing disorders in preschool children: an evidence-based approach. Eur Respir J. 2008;32(4):1096-1110. doi:10.1183/09031936.00002108

6. Bacharier LB, Beigelman A, Calatroni $A$ et al. NIAID sponsored Inner-City Asthma Consortium. Longitudinal Phenotypes of Respiratory Health in a High-Risk Urban Birth Cohort. Am J Respir Crit Care Med. 2019;199(1):71-82. doi:10.1164/ rccm.201801-01900C

7. Garcia-Marcos L, Mallol J, Solé D, Brand PLP, EISL Study Group. International study of wheezing in infants: risk factors in affluent and non-affluent countries during the first year of life. Pediatr Allergy Immunol. 2010;21(5):878-888. doi:10.1111/j.1399-3038.2010.01035.x

8. Sonnenschein-van der Voort AMM, Arends LR, de Jongste JC et al. Preterm birth, infant weight gain, and childhood asthma risk: a metaanalysis of 147,000 European children. J Allergy Clin Immunol. 2014;133(5):1317-1329. doi:10.1016/ j.jaci.2013.12.1082

\title{
KẾT QUẢ ỨNG DỤNG KỸ THUÂ̂T GIẢM ĐAU BẰNG PHÓNG BẾ KHOANG CẠNH SỐNG Ở BỆNH NHÂN CHẤN THƯƠNG NGỰC KÍN
}

\section{TÓM TẮT}

Mục tiêu: Nhận xét chỉ định và đánh giá hiệu quả giảm đau của kỹ thuật phóng bế khoang cạnh sống trong điều trị người bệnh chấn thương ngực kín. Đối tượng và phương pháp: 73 bệnh chấn thương ngực kín điều trị tại Khoa Phẫu thuật lî̀ng ngực - Bệnh viện Quân Y 103, được giảm đau bằng phóng bế khoang cạnh sống. Thời gian từ 01/2018 đến 12/2020. Tiến cứu, mô tả. Kết quả: Tuổi trung bình $52,82 \pm 11,72$ (lớn nhất 92, nhỏ nhất 27). Tỷ lệ nam/nữ là 3,6/1. Nguyên nhân chủ yếu do tai nạn giao thông (58,9\%), tai nạn sinh hoạt $23,3 \%$ và tai nạn lao động $17,8 \%$. Giảm đau bằng phóng bế khoang cạnh sống được chỉ định khi có gãy từ 3 xương sườn trở lên, ở cùng một bên lồng ngực (100\%); 39,7\% trường hợp có gã̃y xương kết hợp, gồm: xương đòn cùng bên (26,0\%), xương bả vai cùng bên $(12,3 \%)$ và xương châu $(1,4 \%)$. Điểm VAS khi nghỉ và khi ho tại các thời điểm lân lượt là: T0 là $6,6 \pm 0,9$ và $8,0 \pm 1,0 ; T 1$ là $5,1 \pm 0,9$ và $6,7 \pm 1,0 ; T 2$ là $4,1 \pm 0,9$ và $5,5 \pm 1,0 ; T 3$ là $3,2 \pm 0,9$ và $4,4 \pm 1,1 ; T 4$ là $2,5 \pm 0,8$ và $3,3 \pm 0,9$, xu hướng giảm có ý nghĩa thống kê $(p<0,05)$. Tỷ lệ biến chứng là 1,4\%. Kết luận: Phóng bế khoang canh sống cho người bệnh CTNNK gãy nhiêu xương sườn ở một bên lồng ngực an toàn, hiệu quả giảm đau tốt.

*Bệnh viện 103, Hoc viện Quân Y Chịu trách nhiệm chính: Vũ Anh Hải Email: vuanhhai.ncs@gmail.com Ngày nhận bài: 16/5/2021

Ngày phàn biện khoa hoc: 12/6/2021

Ngày duyệt bài: 10/7/2021

\section{Vũ Anh Hải*, Lê Việt Anh*}

Từ khóa: Giảm đau cạnh sống; chấn thương ngực kín; gãy xương sườn.

\section{SUMMARY}

\section{THE RESULTS OF THORACIC PARAVERTEBRAL BLOCK FOR PAIN MANAGEMENT IN PATIENTS WITH BLUNT CHEST TRAUMA}

Objectives: Review indications and evaluate the analgesic effectiveness of thoracic paravertebral block in the treatment of patients with blunt chest trauma. Subjects and methods: 73 blunt chest trauma treated at the Department of Thoracic Surgery Military Hospital 103 underwent pain relief by thoracic paravertebral block, from January 2018 to December 2020. Prospective, descriptive. Results: The mean age was $52.8 \pm 11.7(\max 92, \min 27)$. The male/female ratio was 3.6/1. Traffic accidents were the main cause $(58.9 \%)$, followed by daily-life accidents $(23.3 \%)$ and occupational accidents $(17.8 \%)$. The indication of pain relief by paravertebral block for patients who had fractured 3 or more ribs $(100 \%)$, on the same side of the chest; $39.7 \%$ of patients had combined fractures, including: ipsilateral clavicle $(26.0 \%)$, ipsilateral scapula $(12.3 \%)$ and pelvis $(1.4 \%)$. VAS scores at rest or coughing were recorded: T0 was $6.6 \pm 0.9$ and $8.0 \pm 1.0$; T1 was $5.1 \pm 0.9$ and $6.7 \pm 1.0$; T2 was $4.1 \pm 0.9$ and $5.5 \pm 1.0$; T3 was $3.2 \pm 0.9$ and $4.4 \pm 1.1$; T4 was $2.5 \pm 0.8$ and $3.3 \pm 0.9$, the decreasing trend was statistically significant $(p<0.05)$. The complication rate was $1.4 \%$. Conclusion: Thoracic paravertebral block for patients with multiple rib fractures on one side of the ribcage was safe and effective, with good analgesic effect. 
Key words; Blunt chest trauma; rib fructure; paravertebral block.

\section{I. ĐĂT VẤN ĐỀ}

Chẫn thương ngực kín là những tổn thương ở thành ngực hoặc các cơ quan trong lồng ngực nhưng không làm mất sự liên tục của thành ngực, không gây ra tình trạng thông thương giữa khoang màng phổi với bên ngoài. Là tổn thương thường gặp, chiếm khoảng $15 \%$ các cấp cứu ngoại chấn thương, tỳ lệ tử vong dao động từ $9 \%$ đên $60 \%$ [3], [5].

Giảm đau là một trong những vấn đề then chốt trong điều trị chấn thương ngực kín. Hiện nay, nhiêu kỹ thuật giảm đau đã được áp dụng như: phong bễ thần kinh liên sườn, tể ngoài bao cứng phong bế khoang cạnh sống ngực và giảm đau toàn thân bằng chế phẩm Opioid...[1]. Tại Khoa Phẫu thuật lồng ngực - Bệnh viện Quân Y 103, chúng tôi đã thực hiền thường quy kỹ thuật phóng bế khoang cạnh sống ngực trong điêu trị người bệnh chân thương ngực kín. Chúng tôi tiến hành nghiên cứu này nhằm mục tiêu: Nhận xét chỉ định và đánh giá hiệu quả giảm đau của kỹ thuật phóng bế khoang cạnh sống trong điều trị người bệnh chấn thương ngực kín tại Bệnh viện Quân Y 103.

\section{II. ĐỐI TƯợNG VÀ PHƯƠNG PHÁP NGHIÊN CỨU}

2.1. Đối tượng. Toàn bộ người bệnh chấn thương ngực kín (CTNK) được điêu trị tại Khoa Phẫu thuật lồng ngực - Bệnh viện Quân Y 103, được giảm đau bằng phóng bế khoang cạnh sống. Thời gian từ 01/2018 đến 12/2020.

2.2. Phương pháp. Nghiên cứu tiến cứu, mô tả.

2.3. Kỹ thuật phóng bế khoang cạnh sống

*Phương tiện, dụng cụ: Bộ kim gẩy tê ngoài màng cứng; thuốc (Lidocain 1\%, Bupivacain $0,5 \%)$; thước đo độ đau theo thang điểm VAS (Visual Analogue Scale); bơm tiêm điện; dụng cụ tập thở.

*Quy trình kỹ thuật gồm các bước sau [4]:

- Người bệnh ngồi hoặc nằm nghiêng. Người thực hiện kỹ thuật đứng hoặc ngồi ở phía sau lưng bệnh nhân.

- Xác định vị trí đặt catheter: dưới 2 đốt sống so với xương sườn gãy cao nhất, hoặc khoảng giữa xương sườn gãy cao nhất và thấp nhất, cách gai sau đốt sống 2-2,5cm bên tổn thương.

- Sát trùng bằng Betadin $10 \%$, trải săng vô khuẩn vùng đặt catheter.

- Gây tê tại chỗ bằng 2-3 ml lidocain 1\%.

- Chọc kim Touhy vuông góc với mặt da, đây kim đến khi chạm mỏm ngang đốt sống.

- Tháo nòng kim, lắp bơm tiêm có khí, sau đó

chuyển nhẹ hướng kim trườn qua bờ trên của mỏm ngang đốt sống cho đến khi thấy giảm đột ngột lực cản khí trong bơm tiêm (thường sâu vào khoảng $1 \mathrm{~cm}$ ).

- Bơm 5-7 ml khí kiểm tra, nếu thấy nhẹ tay thì kim đã vào khoang cạnh sống.

- Đưa catheter qua kim Touhy vào khoang cạnh sống, chiều dài đoạn catheter nằm trong khoang $2-3 \mathrm{~cm}$. Sau đó cỗ định catheter bằng opsite. Kiểm tra bằng cách hút từ catheter không có máu và có cảm giác áp lực âm tính là được.

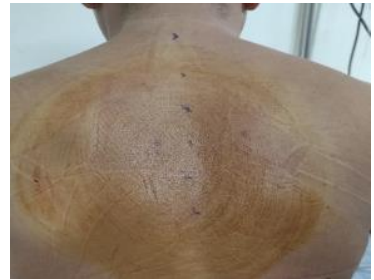

Hình 1. Xác định gai sau; *Nguồn: BN Hoàng Văn H

- Chuyển bệnh nhân sang tư thế nằm ngửa. Sau đó bơm thuốc:

+ Bơm châm trong 3 phút Bupivacain 0,25\% liều $0,5-1 \mathrm{mg} / \mathrm{kg}$. Theo dõi mạch, huyết áp mối 5 phút trong 30 phút sau tiêm.

+ Thiết lập liệu trình bơm liên tục Marcain $0,125 \%$ liêu $0,1 \mathrm{ml} / \mathrm{kg} / \mathrm{h}$ (bằng bơm tiêm điện)

+ Liêu thuốc có thể tăng thêm $1-2 \mathrm{ml} / \mathrm{h}$ sau mỗi lần đánh giá (nếu điểm VAS > 4 khi bệnh nhân ho), với liều tối đa là $0,2 \mathrm{ml} / \mathrm{kg} / \mathrm{h}$.

\subsection{Chỉ tiêu nghiên cứu}

- Nghiên cứu chỉ định theo tổn thương: xương sườn gãy (số lượng, vị trí); các vị trí gãy xương khác và tổn thương kèm theo

- Đánh giá hiệu quả: giảm đau (điểm VAS khi nghỉ và khi ho), thay đổi các chỉ số chức năng hô hấp (tần số thở, SpO2, dung tích khí hít vào tối đa - IC, các chî số khí máu động mạch) tại các thời điểm nghiên cứu: trước thực hiện thủ thuật 30 phút (TO), sau thực hiện thủ thuật phút 30 (T1), 03 giờ (T2), 24 giờ (T3) và 72 giờ (T4).

2.5. Xử lý số liệu. Thu thâp số liệu theo mẫu bệnh án thống nhất, xử lý các thuật toán bằng phần mềm SPSS 22.0.

\section{KẾT QUẢ NGHIÊN CỨU}

3.1. Đăcc điểm chung. Tuổi trung bình là $52,82 \pm 11,72$ (lớn nhất 92, nhỏ nhất 27). Nhóm tuổi từ 40-60 chiếm tỷ lệ cao nhất $(69,9 \%)$.

Tỷ lệ bệnh nhân nam là 78,1\%, nữ 21,9\%. Tỷ lệ nam/ nữ là 3,6/1.

Nguyên nhân chủ yếu là tai nạn giao thông $(58,9 \%)$, tiếp đến là tai nạn sinh hoạt $(23,3 \%)$ 
và tai nạn lao động $(17,8 \%)$.

3.2. Đặc điểm chỉ định theo tổn thương

Bảng 1. Tôn thương gãy xương lồng ngực

\begin{tabular}{|c|c|c|c|c|}
\hline \multicolumn{3}{|c|}{ Xương gãy } & $\begin{array}{c}\text { Tống } \\
(n=73)\end{array}$ & $\begin{array}{l}\text { Tỉ lề } \\
(\%)\end{array}$ \\
\hline \multirow{6}{*}{$\begin{array}{l}\text { Xương } \\
\text { sườn }\end{array}$} & \multicolumn{2}{|c|}{ Bên phải } & 24 & 32,9 \\
\hline & \multirow{2}{*}{\multicolumn{2}{|c|}{$\begin{array}{l}\text { Bên trái } \\
\text { Hai bên }\end{array}$}} & 48 & 65,8 \\
\hline & & & 0 & 0,0 \\
\hline & \multirow{2}{*}{$\begin{array}{l}\text { Số xương } \\
\text { gãy }\end{array}$} & 3 đến 5 & 63 & 86,3 \\
\hline & & $\geq 6$ & 10 & 13,7 \\
\hline & Trung bình & & $1,1 \pm 1,45$ & \\
\hline \multicolumn{3}{|c|}{ Xương bả vai cùng bên } & 9 & 12,3 \\
\hline \multicolumn{3}{|c|}{ Xương đòn cùng bên } & 19 & 26,0 \\
\hline \multicolumn{3}{|c|}{ Gãy xương ức } & 1 & 1,4 \\
\hline
\end{tabular}

Bảng 2. Tốn thương kết hợp

\begin{tabular}{|c|c|c|}
\hline Loại tổn thương & $\begin{array}{c}\text { Số bệnh nhân } \\
(\mathbf{n = 7 3 )}\end{array}$ & $\begin{array}{c}\text { Tỷ lệ } \\
\text { \% }\end{array}$ \\
\hline Chấn thương hàm mặt & 4 & 5,5 \\
\hline Gãy khung chậu & 1 & 1,4 \\
\hline Chấn thương cột sống & 2 & 2,7 \\
\hline Gãy xương tứ chi & 3 & 4,1 \\
\hline
\end{tabular}

\begin{tabular}{|l|l|l|}
\hline Chấn thương bụng kín & 0 & 0,0 \\
\hline
\end{tabular}

\subsection{Hiệu quả}

- Hiêu quả giảm đau, cải thiện chỉ số chức năng hổ hấp

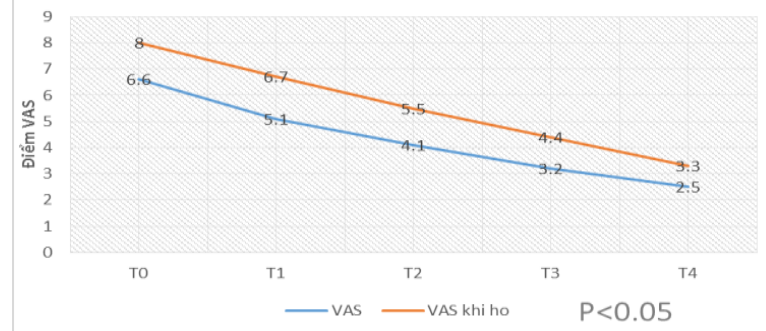

Biểu đồ 1. Điểm VAS lúc nghỉ và khi ho tại các thời điểm nghiên cứu

Điểm VAS khi nghỉ và khi ho giảm dần theo thời gian: ở thời điểm T0 là $6,6 \pm 0,9$ và $8,0 \pm 1,0$; T1 là $5,1 \pm 0,9$ và $6,7 \pm 1,0 ; T 2$ là $4,1 \pm 0,9$ và $5,5 \pm 1,0 ; \mathrm{T} 3$ là $3,2 \pm 0,9$ và $4,4 \pm 1,1 ; \mathrm{T} 4$ là $2,5 \pm 0,8$ và $3,3 \pm 0,9$.

Bảng 3. Chi số đánh giá chức năng hô hấp tại các thời điểm

\begin{tabular}{|c|c|c|c|c|c|c|}
\hline Chỉ tiêu & To & T1 & T2 & T3 & T4 & $\mathbf{P}$ \\
\hline Tân số thở (ck/p) & $21,3 \pm 1,2$ & $20,3 \pm 1$ & $18,6 \pm 1$ & $18,2 \pm 0,5$ & $17,8 \pm 0,7$ & $<0,05$ \\
\hline SpO2 (\%) & $95,7 \pm 2,2$ & $96,9 \pm 1,7$ & $98,3 \pm 1,6$ & $99,0 \pm 1,5$ & $99,6 \pm 0,9$ & $<0,05$ \\
\hline IC (ml) & $\begin{array}{c}700,9 \\
\pm 384,6\end{array}$ & $\begin{array}{l}957,3 \\
458,2\end{array}$ & $\begin{array}{l}1141,4 \\
\pm 477,9\end{array}$ & $\begin{array}{l}1348,8 \\
\pm 498,5\end{array}$ & $\begin{array}{l}1576,2 \\
\pm 444,5\end{array}$ & $<0,05$ \\
\hline $\begin{array}{c}\text { Pa02 động mạch } \\
\text { (mmHg) }\end{array}$ & $79,1 \pm 13,1$ & & $88,8 \pm 17,5$ & & $88,4 \pm 13,2$ & $\begin{array}{c}\mathrm{P} 20 ; \\
\mathrm{P} 40<0,05\end{array}$ \\
\hline $\begin{array}{l}\text { PaC02 động mạch } \\
(\mathrm{mmHg})\end{array}$ & $36,1 \pm 3,6$ & & $35,3 \pm 3,8$ & & $35,7 \pm 4,3$ & $>0,05$ \\
\hline
\end{tabular}

Bảng 4. Tai biến, biến chứng

\begin{tabular}{|c|c|c|}
\hline $\begin{array}{c}\text { Tai biến, biến } \\
\text { chứng }\end{array}$ & $\begin{array}{c}\text { Số bệnh } \\
\text { nhân } \mathbf{( n = 7 3 )}\end{array}$ & $\begin{array}{c}\text { Tỷ lệ } \\
\text { \% }\end{array}$ \\
\hline $\begin{array}{c}\text { Tràn máu khoang } \\
\text { màng phổi }\end{array}$ & 0 & 0 \\
\hline $\begin{array}{c}\text { Tràn khí khoang } \\
\text { màng phổi }\end{array}$ & 0 & 0 \\
\hline Tràn khí trung thất & 0 & 0 \\
\hline Ngộ độc thuốc tề & 0 & 0 \\
\hline Khàn tiếng & 1 & 1,4 \\
\hline
\end{tabular}

Trường hợp người bệnh nhân có biến chứng khàn tiếng: được đặt Catherter tại vị trí ngang mức D4 bên trái, xuất hiện biến chứng sau khi được bơm Bupivacain 0,25\% liều khởi đẩu (20 $\mathrm{ml}$ trong vòng 3 phút), bệnh nhân không có rối loạn hô hấp và tuần hoàn.

\section{BÀN LUÂ̂N}

4.1. Về đặc điểm chung. Nhìn chung các nghiên cứu đều cho thấy chấn thương ngực kín thường gặp ở nhóm bệnh nhân nam giới, trong độ tuổi lao động..

Kết quả của chúng tôi là tương tự. Chúng tôi cũng thây rằng, tai nạn giao thông vẫn là nguyên nhân chính gây nên chấn thương ngực kín (tỷ lệ 58,9\%). Điều đó cho thây, rất cần có những biện pháp cụ thể, phù hợp hơn và quyết liệt hơn trong công tác duy trì việc thực hiện nghiêm luật giao thông nhằm giảm thiểu tai nạn nói chung và CTNK nói riêng.

4.2. Về chỉ định. Số lượng xương sườn gãy càng nhiều mức độ đau càng nặng. Chúng tôi không chỉ định kỹ thuật cho các bệnh nhân CTNK gãy ít hơn 3 xương sườn vì mức độ đau nhẹ, có thể giảm đau bằng các thuốc đường uống và tiêm thông thường. Chỉ định của kỹ thuật là gãy ít nhất 3 xương sườn, ở một bên lồng ngực phù hợp với mức độ tổn thương cũng như hiệu quả đặc thù của kỹ thuật (tác dụng chủ yếu ở phía bên khoang cạnh sống được phong bế), được nhiều tác giả thực hiện [6], [7].

Khi người bệnh có các tổn thương xương kêt hợp, như: gãy xương bả vai, gãy xương đòn cưng bên hoặc đối bên, chúng tôi vẫn sẽ áp dụng phương pháp giảm đau này. Kèm theo có 
thể bổ sung các thuốc giảm đau đường uống hoặc tiêm cho người bệnh khi cần thiết.

ở những bệnh nhân có chấn thương hàm mặt, chi thể, việc sử dụng phương pháp giảm đau này vẫn đạt được hiệu quả tốt trên cơ quan hô hấp, đồng thời không ảnh hưởng tới quá trình theo dõi và điêu trị các tổn thương kèm theo.

Chúng tôi không thực hiện giảm đau cạnh sống cho những người bệnh có chấn thương bụng kín kết hợp vì sẽ gây khó khăn đến quá trình theo dõi, đánh giá tiển triển của bệnh.

Như vậy, kỹ thuật phong bế khoang cạnh sống để giảm đau có thể áp dụng trong hầu hết các trường hợp CTNK, có gãy từ 3 xương sườn trở lên, có thể có các tổn thương kết hợp khác nhưng đã được xử lí và kiểm soát.

\subsection{Về hiệu quả của kỹ thuật}

- Hiệu quả giảm đau: Đánh giá mức độ đau của người bệnh khách quan bằng thang điểm VAS vào các thời điểm nghiên cứu cho thấy hiệu quả giảm đau rõ rệt tại các thời điểm sau khi người bệnh được thực hiện kỹ thuật $(p<0,05)$. Kết quả này tương tự báo cáo của Nguyễn Trường Giang (2018), nghiên cứu 176 bệnh nhân, gãy nhiều xương sườn được giảm đau bằng phong bế khoang cạnh sống ngực (điểm VAS khi nghỉ và khi ho từ $7,1 \pm 1,1$ và $7,8 \pm 0,5$ trước khi thủ thuật giảm còn $3,3 \pm 0,4$ và $4,7 \pm$ 0,4 sau thủ thuật 24 giờ); Nguyển Trung Thành thực hiện kỹ thuật cho bệnh nhân chấn thương ngực và̀ sau mố lồng ngực, tác giả nhận thấy điểm VAS khi nghỉ luôn nhỏ hơn 3 và khi ho luôn nhỏ hơn 4; các tác giả Medha Mohta và $\mathrm{Ge}$ Yeying [6] cũng đều ghi nhận hiệu quả giảm đau tốt của kỹ thuật này.

Hiệu quả giảm đau tốt của kỹ thuật đạt được khi kỹ thuật được thực hiện chính xác, thuốc giảm đau được đưa vào khoang cạnh sống nó có thể lan lên trên, lan xuống dưới, lan ra ngoài khoang gian sườn, lan vào trong khoang ngoài màng cứng và nó sẽ gây ra phong bế thân kinh vận động, thần kinh cảm giác, thần kinh giao cảm ở một bên từ đó làm giảm đau cho bệnh nhân theo các khoanh đoạn da.

- Biến chứng: Trong nghiên cứu, chúng tôi, 01 trường hợp có biến chứng khàn tiếng, đã được dừng bơm thuốc qua Catherter, sau 3 giờ, bệnh nhân hết triệu chứng khàn tiếng và tiếp tục dùng thuốc liều duy trì, không tái xuất hiện khàn tiếng trong suốt quá trình điều trị. Biến chứng này rất hiếm gặp trong thực hành lâm sàng. $M$. Mohta [8], thông báo ca lâm sàng được đặt Catherter tại vị trí ngang mức D3 bên phải, sau tiêm liều khởi đầu 25 phút (15ml Ropivacain), bệnh nhân xuất hiện nói khó và khàn tiếng tạm thời, nội soi xác định có liệt dây thanh bên phải. Tuy vậy, tác giả không đưa ra phân tích và lý giải cho biến chứng này.

Chúng tôi cho rằng: về giải phẫu, đặt Catheter tại vị trí ngang mức D4 là tương ứng vị trí dây thần kinh quặt ngược trái tách từ dây thần kinh X. Với $20 \mathrm{ml}$ Bupivacain $0,25 \%$ có thể làm giảm đau 5 khoang đoạn da vùng lân cận [2]. Do vậy, với liều tiêm liều khởi đầu, khả năng Bupivacain đã lan rộng, phóng bế và ức chế dẫn truyền dây thần kinh quặt ngược trái, gây ra triệu chứng nói khàn.

Các tai biến, biến chứng khác như tụt huyết áp, tràn khí khoang màng phổi, thuốc tê lan vào khoang ngoài màng cứng... không gặp trường hợp nào trong nghiên cứu. Có lẽ do số lượng bệnh nhân còn ít, bên cạnh đó việc tuân thủ nghiêm ngặt quy trình kĩ thuật cũng giúp giảm thiểu được tai biến, biến chứng xảy ra.

\section{KẾT LUẬN}

Phóng bế khoang cạnh sống cho người bệnh CTNK gãy nhiều xương sườn (trung bình $4,1 \pm$ 1,45 xương, $100 \%$ bệnh nhân gãy từ 3 xương trở lên), ở một bên lồng ngực hiệu quả giảm đau tốt, an toàn, biến chứng tỷ lệ thẩp $(1,4 \%)$.

\section{TÀI LIẸU THAM KHẢO}

1. Beard1 L., Billy H., Catherine S., et al. (2020) "Analgesia of Patients with Multiple Rib Fractures in Critical Care: A Survey of Healthcare Professionals in the UK", Indian Journal of Critical Care Medicine (2020): 10.5005/jp-journals-10071-23375.

2. Cheema S. P., D. Ilsley, J. Richardson, and, Sabanathan S. (1995), "A thermographic study of paravertebral analgesia", 'Anaesthesia, 50(2), 118-21.

3. Dogrul B. N., Kiliccalan I., Asci E. S., et al. (2020), "Blunt trauma related chest wall and pulmonary injuries: An overview", Chin J Traumatol, 23(3), 125-138.

4. Eason MJ., Wyatt R., (1979), "Paravertebral thoracic block-a reappraisal", Anaesthesia; 34: 638 - 642.

5. Eghbalzadeh K., Sabashnikov A., Zeriouh M., et al. (2018), "Blunt chest trauma: a clinical chameleon", Heart, 104(9), 719-724.

6. Yeying G., Liyong Y., Yuebo1 C., et al. (2017), "Thoracic paravertebral block versus intravenous patientcontrolled analgesia for pain treatment in patients with multiple rib fractures", Journal of International Medical Research 2017, Vol. 45(6) 2085-2091.

7. Karmakar M. K., Critchley L. A., Ho A. M., et al. (2003), "Continuous thoracic paravertebral infusion of bupivacaine for pain management in patients with multiple fractured ribs", Chest, 123(2), 424-31.

8. Mohta M., Ophrii L.E., Agarwal D., et al. (2011), "Vocal cord palsy: an unusual complication of paravertebral block.", Anaesth Intensive Care. 2011 Sep;39(5):969-71. 